EPJ Web of Conferences 27, 00004 (2012)

DOI: $10.1051 /$ epjconf/20122700004

(C) Owned by the authors, published by EDP Sciences, 2012

\title{
Importance of Nuclear Data Uncertainties in Criticality Calculations
}

\author{
C. Ceresio ${ }^{1}$, O. Cabellos ${ }^{1,2}$, J.S. Martínez ${ }^{1}$, and C.J. Diez ${ }^{1}$ \\ ${ }^{1}$ Department of Nuclear Engineering, Universidad Politécnica de Madrid, Spain \\ ${ }^{2}$ Instituto de Fusión Nuclear, Universidad Politécnica de Madrid, Spain
}

\begin{abstract}
The aim of this paper is to study the importance of nuclear data uncertainties in the prediction of the uncertainties in $\mathrm{k}_{\mathrm{eff}}$ for LWR (Light Water Reactor) unit-cells. The first part of this work is focused on the comparison of different sensitivity/uncertainty propagation methodologies based on TSUNAMI and MCNP codes; this study is undertaken for a fresh-fuel at different operational conditions. The second part of this work studies the burnup effect where the indirect contribution due to the uncertainty of the isotopic evolution is also analyzed.
\end{abstract}

\section{Introduction}

It has been long recognized throughout the reactor physics community that for the establishment of Light Water Reactor (LWR) best-estimate calculations for design margins and safety analysis are needed. In addition, a comprehensive uncertainty analysis is very important to assess appropriate design margins, and to point out where further efforts are required to reduce these uncertainties. As a consequence of many meetings, the international expert community in reactor physics, thermal-hydraulics, and uncertainty and sensitivity analysis, had decided that a first step was to define an OECD benchmark for Uncertainty Analysis in Modelling (UAM) for design, operation, and safety analysis of LWRs. Polytechnic University of Madrid (UPM) has participated in the Phase 1 (Neutronics Phase) of this benchmark in the Exercise I-1 [1].

The intention of the first part of this work is to propagate the nuclear data uncertainties both in $\mathrm{k}_{\mathrm{eff}}$ and multi-group microscopic cross-sections used as an input by lattice reactor physics codes. In Section 3, it is shown how the $\mathrm{k}_{\mathrm{eff}}$ sensitivity coefficients are calculated by MCNP/PERT card and the TSUNAMI code for a LWR fresh fuel specified in the Benchmark. The most important contributions by isotopes and reactions have been identified.

In Section 4, the $\mathrm{k}_{\mathrm{eff}}$ uncertainty in burnup calculations has been calculated using the TSUNAMI code. Its contribution due to the uncertainties in fuel isotopic concentrations is also predicted.

\section{Problem Description}

In this work, a PWR unit-cell has been selected. It has been taken from the UAM Benchmark Exercise I-1 (Cell Physics). Table 1 shows a two-dimensional fuel pin-cell configuration of the PWR test.

Table 1. Configuration of PWR/TMI-1 unit cell.

\begin{tabular}{|l|c|}
\hline \multicolumn{1}{|c|}{ Parameter } & Value \\
\hline Unit cell pitch, $(\mathrm{mm})$ & 14.427 \\
\hline Fuel pellet diameter, $(\mathrm{mm})$ & 9.391 \\
\hline Fuel pellet material & $\mathrm{UO}_{2}$ \\
\hline Fuel density, $\left(\mathrm{g} / \mathrm{cm}^{3}\right)$ & 10.283 \\
\hline Fuel enrichment, w/o & 4.85 \\
\hline Cladding outside diameter, $(\mathrm{mm})$ & 10.928 \\
\hline Cladding thickness, $(\mathrm{mm})$ & 0.673 \\
\hline Cladding material & Zircaloy-4 \\
\hline Cladding density, $\left(\mathrm{g} / \mathrm{cm}^{3}\right)$ & 6.55 \\
\hline Gap material & $\mathrm{He}$ \\
\hline Moderator Material & $\mathrm{H}_{2} \mathrm{O}$ \\
\hline
\end{tabular}

Table 2. Operational conditions for PWR/TMI-1 unit cell.

\begin{tabular}{|l|c|c|}
\hline \multicolumn{1}{|c|}{ Operational conditions } & HZP & HFP \\
\hline Fuel temperature $(\mathrm{K})$ & 551 & 900 \\
\hline Cladding temperature (K) & 551 & 600 \\
\hline Moderator (coolant) temperature (K) & 551 & 562 \\
\hline Moderator (coolant) density $\left(\mathrm{Kg} / \mathrm{m}^{3}\right)$ & 766 & 748.4 \\
\hline Reactor Power (MW) & 2.772 & 2772 \\
\hline
\end{tabular}


Operational conditions at Hot Zero Power (HZP) and Hot Full Power (HFP) are defined in Exercise I-1 to be analyzed. Table 2 details these reactor conditions.

\section{A Comparison of Different Sensitivity and Uncertainty Propagation Methodologies}

In order to perform the sensitivity/uncertainty analysis two methodologies have been used. The first methodology is based on a coupled system MCNP/NJOY/SUSD3D, and the second one is performed with the TSUNAMI code.

\subsection{Sensitivity/Uncertainty Based on MCNP}

Using MCNP, the perturbation approach relies in principle on "NJOY + MCNP5 + SUSD3D" calculations. Fig. 1 shows a scheme of the methodology used in this work [2].

Unit-cells are modelled with MCNP5 and crosssection data are taken from ENDF/V-II.0 processed with NJOY in ACE format at different temperatures. To compute sensitivity coefficients the MCNP/PERT card has been used. The PERT-card is created specifying that the relevant material is replaced by the perturbed material in each of the cells in which the material is present. In this work, 880 PERT-cards are defined to take into account sensitivities for 4 isotopes $\left(\mathrm{O}^{16}\right.$ and $\left.\mathrm{U}^{234,235,238}\right)$ and 5 reactions (elastic, inelastic, capture, fission and $(n, 2 n))$ in a 44 energy group structure. Figs. 2 and 3 show $\mathrm{U}^{235}$ and $\mathrm{U}^{238}$ capture reaction sensitivities for PWR and BWR unit-cells at HZP.

It should be noted that the PERT-card of MCNP5 has several limitations: i) large perturbations require higher than second order terms to avoid inaccurate tallies, ii) the track length estimate of $\mathrm{k}_{\mathrm{eff}}$ in KCODE criticality calculations assumes the fundamental eigenvector (fission distribution) is unchanged in the perturbed configuration, then, the accuracy is limited because the "differential operator method" does not account for this perturbation, iii) scattering affects the fission source spatial distribution more than capture does, so the error in fission source can be large, and iv) it cannot calculate chi and nu-bar sensitivity coefficients.

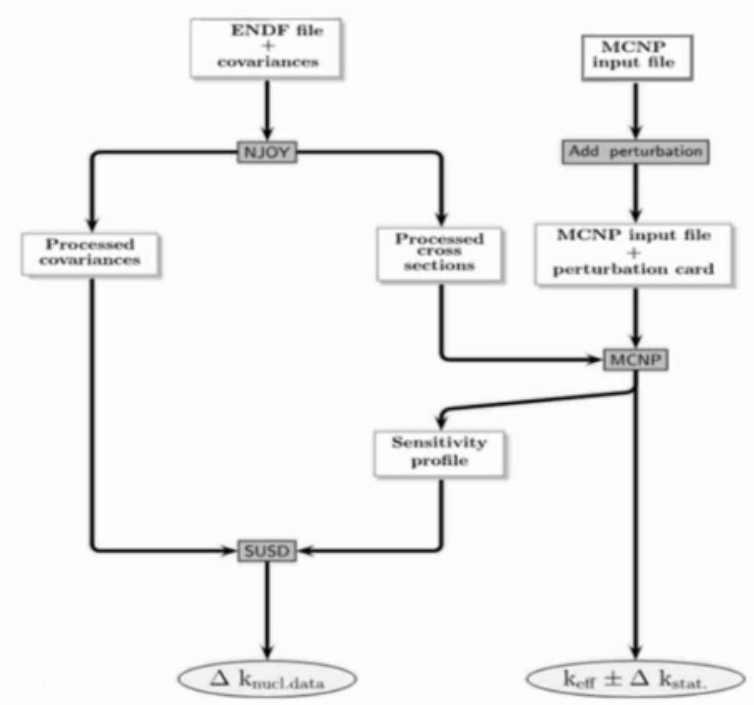

Fig. 1. Scheme of the methodology [2].

For these reactions, covariance data were taken from the SCALE6.0/COVA library [3]. This uncertainty library is given in 44-groups written in COVERX format. And, it has been processed in ENDF format with ANGELO and LAMBDA codes. NJOY code, with ERRORR and COVR modules, is used to plot these values (see Fig. 4).

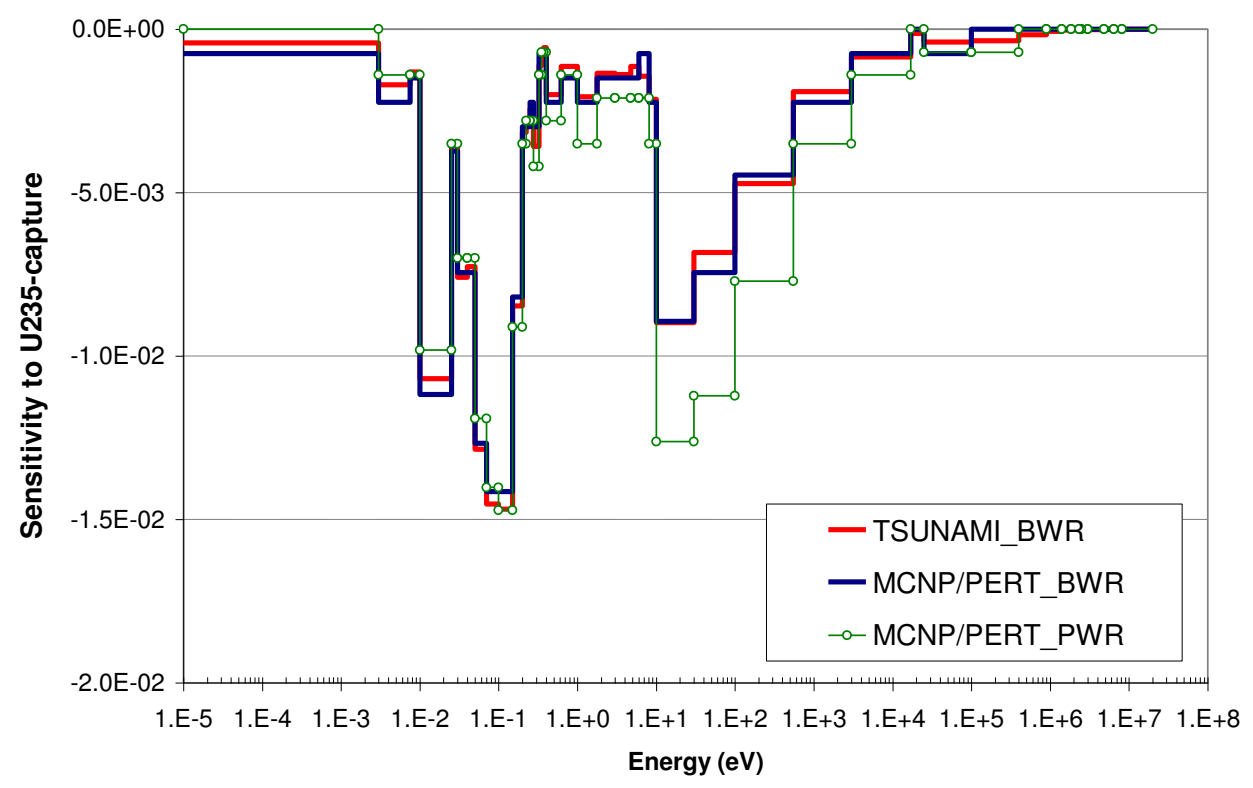

Fig. 2. $\mathrm{U}^{235}$-capture sensitivity coefficients for PWR and BWR at HZP calculated by TSUNAMI and MCNP/PERT. 


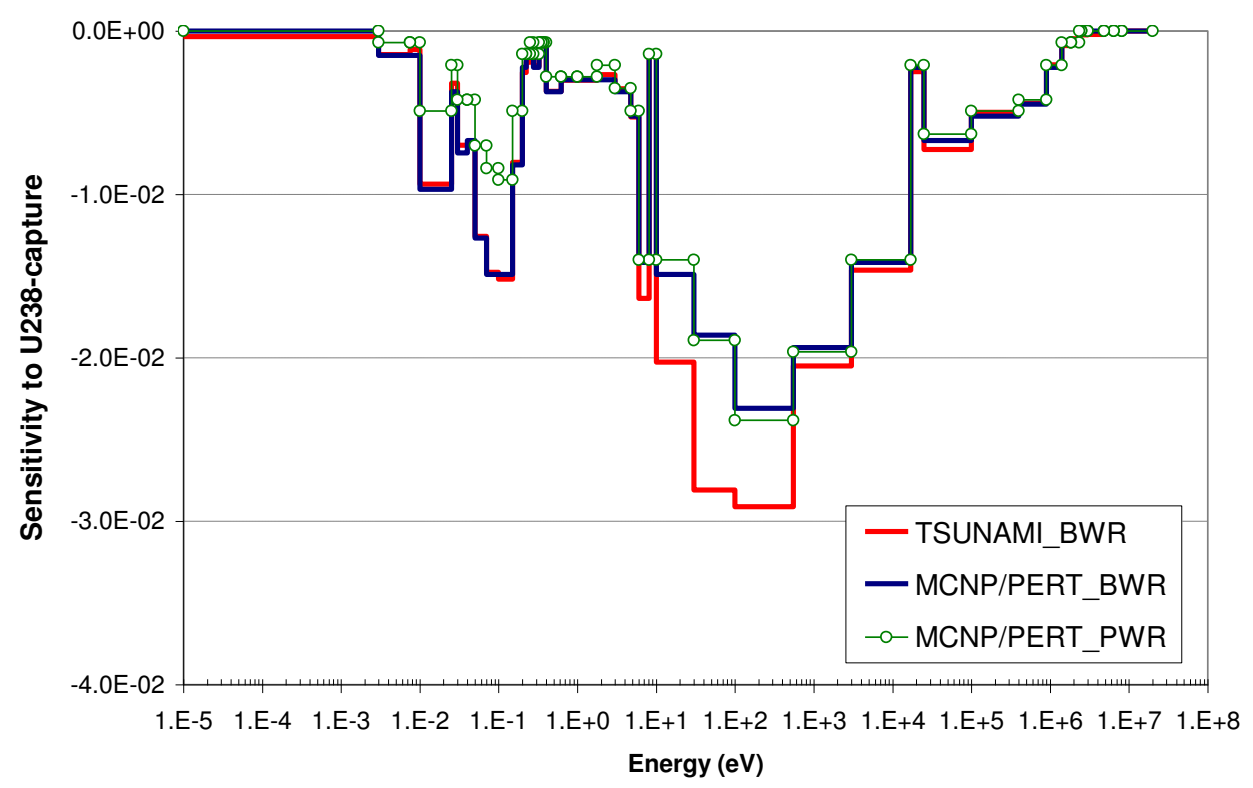

Fig. 3. $\mathrm{U}^{238}$-capture sensitivity coefficients for PWR and BWR at HZP calculated by TSUNAMI and MCNP/PERT.

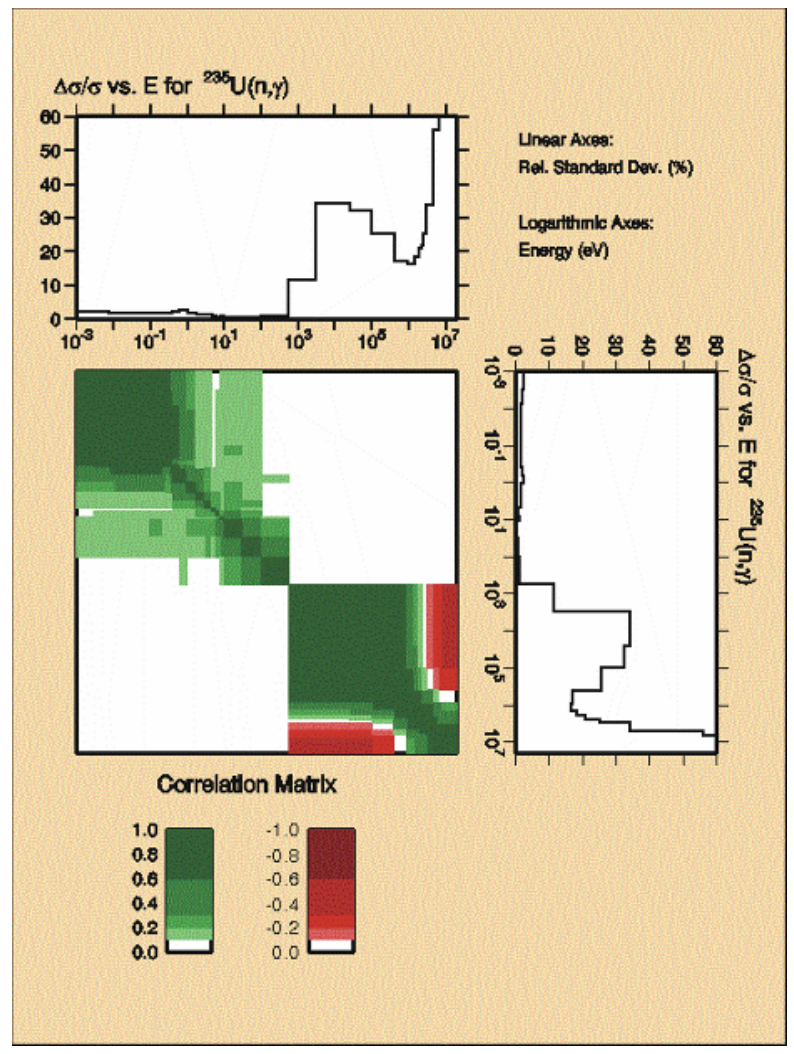

Fig. 4. $U^{235}$-capture covariances from SCALE6.0/COVA library given in 44 groups

Finally, the sensitivity profiles (elastic, inelastic, capture, fission and $(\mathrm{n}, 2 \mathrm{n}))$ and the processed covariance data are used in SUSD3D code to predict the uncertainty and the most important contributions to this uncertainty. Table 3 summarizes the uncertainty results for PWR unit-cell Benchmark based on this methodology.

\subsection{Sensitivity and Uncertainty Analysis with TSUNAMI Code}

The TSUNAMI code is used to compute the sensitivity of $\mathrm{k}_{\mathrm{eff}}$ due to cross-section data. SCALE6.0/COVA cross-section-covariance data are used in the calculation of the uncertainty in $\mathrm{k}_{\mathrm{eff}}$ due to uncertainties in the evaluated nuclear data. A sensitivity data file containing the sensitivity of $\mathrm{k}_{\text {eff }}$ to each reaction of each nuclide on a group-wise basis is created. Additionally, the sensitivity of $\mathrm{k}_{\mathrm{eff}}$ for each nuclide and each reaction of each mixture and material zone is available on a groupwise basis.

In Fig. 2, a good agreement between MCNP/PERT and TSUNAMI sensitivities for the $\mathrm{U}^{235}$ capture reaction can be seen while in Fig. 3, for the capture reaction of the $\mathrm{U}^{238}$, a large difference has been found in the range between $10 \mathrm{eV}$ and $1000 \mathrm{eV}$ of energy. This difference is due to the limitation of the MCNP/PERT card related with an unchanged fission distribution in the sensitivity prediction.

\subsection{Uncertainty Results}

In Table 3, the results for the PWR unit-cell are summarized, where $\mathrm{k}_{\mathrm{inf}}$, absorption and fission reaction rates for $\mathrm{U}^{235}$ and $\mathrm{U}^{238}$, and their associated uncertainties due to multi-group cross-sections covariance matrices are shown. In addition, the five most important nuclide reactions and nuclear data that contribute to uncertainty in $\mathrm{k}_{\mathrm{eff}}$ are identified: $\mathrm{U}^{238}(\mathrm{n}, \gamma)$, $\mathrm{U}^{235}(\mathrm{n}, \gamma), \mathrm{U}^{235}$ (n,fission), $\mathrm{U}^{238}(\mathrm{n}, \mathrm{n}), \mathrm{U}^{235}$ (nubar) and $\mathrm{U}^{235}$ (fission, capture). 
Table 3. Uncertainty results for PWR(TMI-1) problem.

\begin{tabular}{|c|c|c|c|c|c|}
\hline & & \multicolumn{2}{|c|}{ Hot Zero Power } & \multicolumn{2}{|c|}{ Hot Full Power } \\
\hline \multirow{3}{*}{\multicolumn{2}{|c|}{$\begin{array}{r}\text { Kinf } \\
\text { Uncertanties }(\% \Delta \mathrm{k} / \mathrm{k})\end{array}$}} & MCNP/PERT & TSUNAMI & MCNP/PERT & TSUNAMI \\
\hline & & $1.42701 \pm 0.00034$ & $1.42190 \pm 0.00310$ & $1.41130 \pm 0.00036$ & $1.40510 \pm 0.00290$ \\
\hline & & 0.37 & 0.50 & 0.37 & 0.51 \\
\hline \multirow{6}{*}{$\begin{array}{l}\text { Top contributions to } \\
\text { the uncertainty }\end{array}$} & $\mathbf{U}^{238}(n, \gamma)$ & 0.25 & 0.29 & 0.26 & 0.30 \\
\hline & $\mathbf{U}^{235}(\mathbf{n}, \gamma)$ & 0.21 & 0.21 & 0.21 & 0.21 \\
\hline & $\mathbf{U}^{235}$ (n,fission) & 0.08 & 0.08 & 0.08 & 0.08 \\
\hline & $\mathbf{U}^{238}\left(n, n^{\prime}\right)$ & 0.09 & 0.11 & 0.09 & 0.11 \\
\hline & $\mathbf{U}^{235}$ (fiss,capture) & 0.15 & 0.11 & 0.15 & 0.10 \\
\hline & $\mathbf{U}^{235}(v)$ & - & 0.26 & - & 0.26 \\
\hline \multirow[t]{2}{*}{ Absortion rate $\left(\mathrm{cm}^{-3} \mathrm{~s}^{-1}\right)$} & $\mathbf{U}^{235}$ & $2.09 \mathrm{E}+09$ & $2.11 \mathrm{E}+09$ & $2.10 \mathrm{E}+12$ & $2.13 \mathrm{E}+12$ \\
\hline & $\mathbf{U}^{238}$ & $3.99 \mathrm{E}+09$ & $4.04 \mathrm{E}+09$ & $4.18 \mathrm{E}+12$ & $4.24 \mathrm{E}+12$ \\
\hline \multirow[t]{2}{*}{ Uncertainties (\%) } & $\mathbf{U}^{235}$ & 0.36 & - & 0.37 & - \\
\hline & $\mathbf{U}^{238}$ & 0.54 & - & 0.56 & - \\
\hline \multirow[t]{2}{*}{ Fission rate $\left(\mathrm{cm}^{-3} \mathrm{~s}^{-1}\right)$} & $\mathbf{U}^{235}$ & $8.93 \mathrm{E}+09$ & $8.92 \mathrm{E}+09$ & $8.91 \mathrm{E}+12$ & $8.91 \mathrm{E}+12$ \\
\hline & $\mathbf{U}^{238}$ & $4.88 \mathrm{E}+08$ & $4.91 \mathrm{E}+08$ & $4.99 \mathrm{E}+11$ & $5.04 \mathrm{E}+11$ \\
\hline \multirow[t]{2}{*}{ Uncertainties (\%) } & $\mathbf{U}^{235}$ & 0.40 & - & 0.41 & - \\
\hline & $\mathbf{U}^{238}$ & 3.60 & - & 3.65 & - \\
\hline
\end{tabular}

\section{Uncertainty Analysis in Burnup Applications}

The uncertainty methodology presented in this work is based on two steps, see Fig. 5 [4]. In a first step, a coupled neutron-depletion calculation is carried out only once, taken the best-estimated values for neutron spectra. When solving the transport equation to calculate the flux distribution for each time step, neither uncertainties in the input parameters nor statistical fluctuations are taken into account. This is called the best-estimated multi-step calculation.

In a second step, the uncertainty analysis to evaluate the influence of the uncertainties in nuclear data involved in the transmutation process on the isotopic inventory is accomplished by the ACAB [5] code. In this work, zero uncertainties are assumed in: (i) the initial nuclide density, (ii) the integrated neutron flux, (iii) and spectrum. In summary, the sources of uncertainty in this transmutation calculation are only due to basic nuclear data.

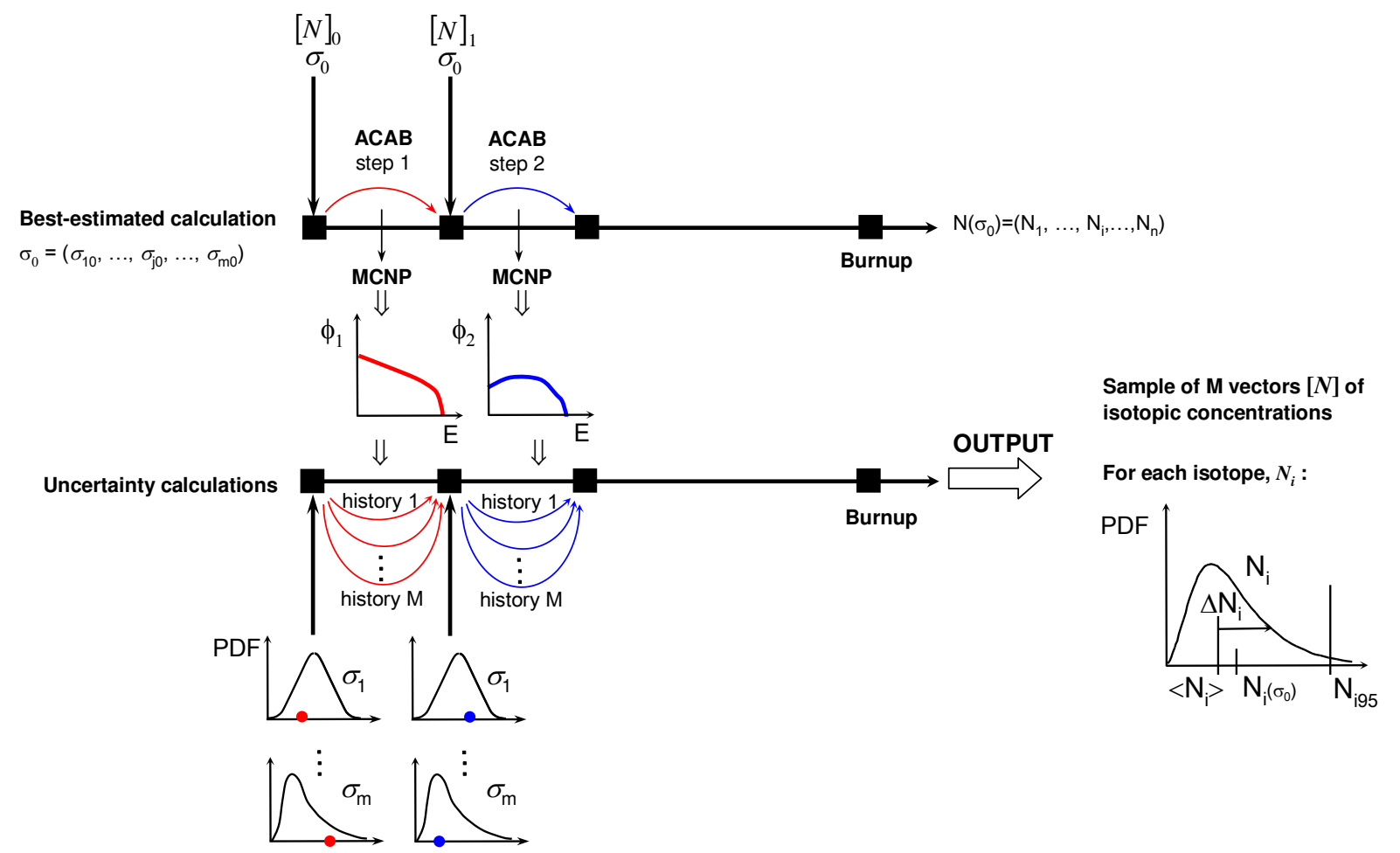

Fig. 5. Monte Carlo method scheme implemented to propagate uncertainties in fuel isotopic concentrations [4]. 
A random vector $\alpha=(\sigma, \lambda, \gamma)$ is defined containing all the cross sections, decays and fission yields involved in the problem. Each concentration at time $t, \mathrm{~N}(\mathrm{t})$, is a function of the random vector $\alpha$. To perform the uncertainty analysis, a random simulation or Monte Carlo (MC) method has been used, assuming a log-normal probability distribution, that is, $\log (\alpha / \hat{\alpha}) \rightarrow N(0, V)$, where $\mathrm{V}$ is the variance matrix of the nuclear data relative error. Then, ACAB code is used to propagate the overall nuclear data uncertainties. A 300 histories sample size is sufficient to reach convergence of the Monte Carlo technique for this application. A statistical analysis of the results allows assessing the uncertainties in the calculated number densities. The decay and fission yield uncertainty data have been taken into account and processed directly from JEFF-3.1.1 [6]. The neutron cross-section uncertainty data have been taken from the EAF2010/UN[7] library and SCALE6.0/COVA-44G [3].

An unit-cell burnup of $44 \mathrm{GWd} / \mathrm{TMU}$ and 5 years of cooling time has been defined in this work to assess the impact of nuclear data uncertainties.

\subsection{Uncertainty Isotopic Prediction}

In Table 4, it can be seen that actinide concentration uncertainties due to decay data uncertainties remain very low. Only $\mathrm{Cm}^{243}$ reaches $0.8 \%$ due to the $6.7 \%$ half-life relative error of ${ }^{243} \mathrm{Cm}$. Regarding cross-section data uncertainties, it can be seen that EAF2010/UN does not fulfil accuracy requirements for $\mathrm{Cm}^{243}$ and $\mathrm{Cf}^{250,251,252}$. SCALE6/COVA does not fulfil for ${ }^{250,251,252} \mathrm{Cf}$. For major actinides, SCALE6.0/COVA fulfils the requirements better, but some minor actinides are better fulfilled with EAF2010/UN.

Table 5 shows the light-elements uncertainty for the irradiated unit-cell. For decay data uncertainties, the isotope $\mathrm{Eu}^{151}$ reaches a maximum uncertainty of $7.1 \%$ as a consequence of the $6.7 \%$ relative error in the half-life of $\mathrm{Sm}^{151}$. The uncertainties due to fission yields remain below $5 \%, \mathrm{Mo}^{95}$ with $4.5 \%$ (with high sensitivity to $\mathrm{Zr}^{95}$ fission yield) and $\mathrm{Sm}^{149}$ with $4.7 \%$ (with high sensitivity to $\mathrm{Pm}^{149}$ fission yield). EAF2010/UN does not fulfil the target below $5 \%$ for $\mathrm{Eu}^{154,155}$ and $\mathrm{Gd}^{154,155}$, and SCALE6/COVA does not fulfil the target for $\mathrm{Sm}^{149}, \mathrm{Eu}^{155}$ and $\mathrm{Gd}^{155}$. In the case of $\mathrm{Gd}^{155}$ (generated by $\beta$-decay of $\mathrm{Eu}^{155}$ ), it shows higher sensitivities to $\mathrm{Eu}^{153,155}$ (n, $\left.\gamma\right)$ reaction and $\mathrm{Eu}^{155}$ fission yield. For $\mathrm{Sm}^{149}$ (mainly produced by $\beta$-decay of $\mathrm{Pm}^{149}$ ) the higher sensitivities are due to $\operatorname{Sm}^{149}(\mathrm{n}, \gamma)$ and $\mathrm{Pm}^{149}$ fission yield .

\subsection{Uncertainty Criticality Safety Evaluation}

The $\mathrm{k}_{\text {eff }}$ uncertainty is calculated taking into account the nuclear data uncertainties, where it is explicitly dependent on the nuclear data (e.g. cross-sections, nu-bar, ...) and implicitly dependent on the number densities which characterize the system.

The first explicit term is calculated using the TSUNAMI code showing in Fig. 6 the evolution with burnup. TSUNAMI predicts $\sim 0.50 \%$ relative error in $\mathrm{k}_{\text {eff }}$ for fresh fuel where the most important reactions and nuclear data are: $\mathrm{U}^{235}\left(\right.$ nubar), $\mathrm{U}^{238}\left(\mathrm{n}, \mathrm{n}^{\prime}\right)$ and $\mathrm{U}^{235}(\mathrm{n}, \gamma)$. At shutdown, the relative error in $\mathrm{k}_{\text {eff }}$ reaches $\sim 0.90 \%$. The most important reactions and nuclear data are: $\mathrm{Pu}^{239}$ (nubar), $\mathrm{U}^{238}\left(\mathrm{n}, \mathrm{n}^{\prime}\right), \mathrm{U}^{238}(\mathrm{n}, \gamma), \mathrm{Pu}^{239}$ (n,fission) and $\mathrm{Pu}^{239}$ (fission capture).

The second implicit term indicates the indirect term due to the uncertainty in nuclide inventory. The sensitivity coefficients for isotopes in spent fuel are shown in Fig. 7. It can be seen that the most important sensitivities for actinides are: $\mathrm{U}^{235,238}$ and $\mathrm{Pu}^{239,240,241}$. For this implicit uncertainty, the importance of different sources of nuclear data uncertainties is identified. At shutdown, it can be concluded that decay data has a negligible effect compared with the explicit term of $\mathrm{k}_{\mathrm{eff}}$ uncertainty, with only $\sim 10 \mathrm{pcm}$. However, larger uncertainties are induced by fission yield data uncertainties with $\sim 200 \mathrm{pcm}$, and cross-section uncertainties with $\sim 300 \mathrm{pcm}$ and $\sim 150 \mathrm{pcm}$, for EAF2010/UN and SCALE6.0/COVA, respectively.

\section{Conclusions}

This work highlights the importance that the uncertainties in basic nuclear data may have on the final result $\mathrm{k}_{\mathrm{eff}}$ and how the burnup can affect the final uncertainties. An uncertainty in fresh fuel $\mathrm{k}_{\mathrm{eff}}$ of about $\sim 500 \mathrm{pcm}$ has been estimated from the results and the largest contributions to the uncertainty are: $\mathrm{U}^{238}(\mathrm{n}, \gamma), \mathrm{U}^{235}$ (nubar) and ${ }^{235} \mathrm{U}(\mathrm{n}, \gamma)$. At high burnup, the $\mathrm{k}_{\text {eff }}$ uncertainty is increased up to $\sim 900$ pcm, with $\mathrm{Pu}^{239}$ (nubar) being the most important contribution, and the uncertainties in the isotopic inventory will increase this uncertainty additionally in $\sim 250 \mathrm{pcm}$.

According with these uncertainty results for burnup calculations, the OECD/UAM Working Group has considered continuing these activities of great interest, promoting the use of other sensitivity/uncertainty depletion methodologies to assess the importance of nuclear data uncertainties. TMC (Total Monte Carlo,NRG) NUDUNA (AREVA) and XSUSA (GRS) methodologies should be candidates to deal with this problem in future works.

Work performed in the framework of the agreement P090531725 on Burnup Credit Criticality Safety and P110530207 on Uncertainty Propagation in Criticality Calculations between the Spanish Nuclear Safety Council (CSN, Consejo de Seguridad Nuclear) and the Polytechnical University of Madrid. 
Table 4. Calculated uncertainties in actinides due to crosssections and decay data uncertainties.

\begin{tabular}{|c|c|c|c|}
\hline \multirow[b]{2}{*}{ Isotope } & \multirow{2}{*}{$\begin{array}{c}\text { Decay } \\
\text { Data } \\
\text { JEFF-3.1.1 }\end{array}$} & \multicolumn{2}{|c|}{ Cross-section } \\
\hline & & $\begin{array}{c}\text { EAF2010 } \\
3 \text { groups } \\
\end{array}$ & $\begin{array}{c}\text { SCALE6.0 } \\
44 \text { groups } \\
\end{array}$ \\
\hline U233 & 0.2 & 0.6 & 1.3 \\
\hline $\mathrm{U} 234$ & 0.1 & 0.8 & 1.8 \\
\hline $\mathrm{U} 235$ & 0.0 & 0.1 & 0.2 \\
\hline U236 & 0.0 & 0.4 & 0.2 \\
\hline $\mathrm{U} 238$ & 0.0 & 0.1 & 0.0 \\
\hline Np237 & 0.0 & 0.6 & 0.5 \\
\hline $\mathrm{Pu} 238$ & 0.0 & 2.4 & 0.3 \\
\hline $\mathrm{Pu} 239$ & 0.0 & 0.5 & 0.5 \\
\hline $\mathrm{Pu} 240$ & 0.0 & 1.1 & 0.5 \\
\hline $\mathrm{Pu} 241$ & 0.1 & 0.9 & 0.4 \\
\hline $\mathrm{Pu} 242$ & 0.0 & 1.1 & 0.7 \\
\hline Am241 & 0.2 & 0.9 & 0.4 \\
\hline Am243 & 0.0 & 1.3 & 1.7 \\
\hline $\mathrm{Cm} 242$ & 0.4 & 3.1 & 0.7 \\
\hline $\mathrm{Cm} 243$ & 0.8 & 4.4 & 3.2 \\
\hline $\mathrm{Cm} 244$ & 0.1 & 1.4 & 1.8 \\
\hline $\mathrm{Cm} 245$ & 0.0 & 1.6 & 3.8 \\
\hline $\mathrm{Cm} 246$ & 0.0 & 1.8 & 2.7 \\
\hline $\mathrm{Cm} 247$ & 0.0 & 2.1 & 3.2 \\
\hline $\mathrm{Cm} 248$ & 0.0 & 2.9 & 3.7 \\
\hline $\mathrm{Cf} 250$ & 0.2 & 4.6 & 4.7 \\
\hline $\mathrm{Cf} 251$ & 0.1 & 5.0 & 5.2 \\
\hline Cf252 & 0.4 & 4.6 & 4.4 \\
\hline
\end{tabular}

Table 5. Calculated uncertainties in light-elements due to crosssections, fission yields and decay data uncertainties.

\begin{tabular}{|c|c|c|c|c|}
\hline \multirow[b]{2}{*}{ Isotope } & \multirow[b]{2}{*}{$\begin{array}{c}\text { Fission } \\
\text { Yields } \\
\text { JEFF-3.1.1 } \\
\end{array}$} & \multirow[b]{2}{*}{ 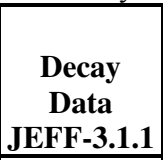 } & \multicolumn{2}{|c|}{ Cross-section } \\
\hline & & & $\begin{array}{l}\text { EAF2010 } \\
3 \text { groups }\end{array}$ & $\begin{array}{c}\text { SCALE6.0 } \\
44 \text { groups }\end{array}$ \\
\hline Mo95 & 4.5 & \begin{tabular}{|l|}
0.0 \\
\end{tabular} & 0.4 & 0.2 \\
\hline Tc99 & 1.2 & 0.0 & 0.4 & 0.2 \\
\hline Ru101 & 1.2 & 0.0 & 0.3 & 0.2 \\
\hline Ru106 & 1.8 & 0.9 & 0.5 & 0.2 \\
\hline Rh103 & 1.3 & 0.0 & 0.7 & 0.3 \\
\hline Ag109 & 1.3 & 0.0 & 2.3 & 0.3 \\
\hline Cs133 & 0.9 & 0.0 & 0.3 & 0.2 \\
\hline Cs134 & 0.9 & 0.0 & 1.1 & 0.8 \\
\hline Cs135 & 0.9 & 0.0 & 0.7 & 0.4 \\
\hline Cs137 & 1.2 & 0.0 & 0.3 & 0.2 \\
\hline La139 & 1.2 & 0.0 & 0.3 & 0.1 \\
\hline $\mathrm{Ce} 140$ & 1.2 & 0.0 & 0.3 & 0.1 \\
\hline $\mathrm{Ce} 142$ & 1.3 & 0.0 & 0.3 & 0.1 \\
\hline $\mathrm{Ce} 144$ & 1.7 & 0.4 & 0.5 & 0.2 \\
\hline $\mathrm{Nd} 142$ & 1.3 & 0.0 & 1.6 & 0.5 \\
\hline $\mathrm{Nd} 143$ & 1.1 & 0.0 & 0.9 & 0.3 \\
\hline $\mathrm{Nd} 145$ & 1.1 & 0.0 & 0.3 & 0.2 \\
\hline $\mathrm{Nd} 146$ & 0.8 & 0.0 & 0.3 & 0.2 \\
\hline $\mathrm{Nd} 148$ & 0.9 & 0.0 & 0.3 & 0.2 \\
\hline $\mathrm{Nd} 150$ & 1.4 & 0.0 & 0.3 & 0.2 \\
\hline Sm147 & 1.2 & 0.0 & 0.4 & 1.0 \\
\hline Sm148 & 1.3 & 0.0 & 0.4 & 0.4 \\
\hline Sm149 & 4.7 & 0.0 & 2.5 & 4.5 \\
\hline Sm150 & 0.8 & 0.0 & 0.4 & 0.7 \\
\hline Sm151 & 2.7 & 0.3 & 2.4 & 2.1 \\
\hline Sm152 & 0.8 & 0.0 & 0.6 & 0.7 \\
\hline Sm154 & 1.0 & 0.0 & 0.4 & 0.2 \\
\hline Eu151 & 2.7 & 7.1 & 2.3 & 2.1 \\
\hline Eu153 & 0.7 & 0.0 & 3.2 & 0.5 \\
\hline Eu154 & 0.7 & 0.0 & 7.6 & 3.1 \\
\hline Eu155 & 1.3 & 0.2 & 7.5 & 4.0 \\
\hline Gd154 & 0.7 & 0.0 & 5.6 & 2.4 \\
\hline Gd155 & 1.3 & 0.2 & 7.5 & 4.0 \\
\hline Gd156 & 0.9 & 0.0 & 1.9 & 0.5 \\
\hline Gd158 & 1.3 & 0.0 & 1.0 & 0.5 \\
\hline
\end{tabular}




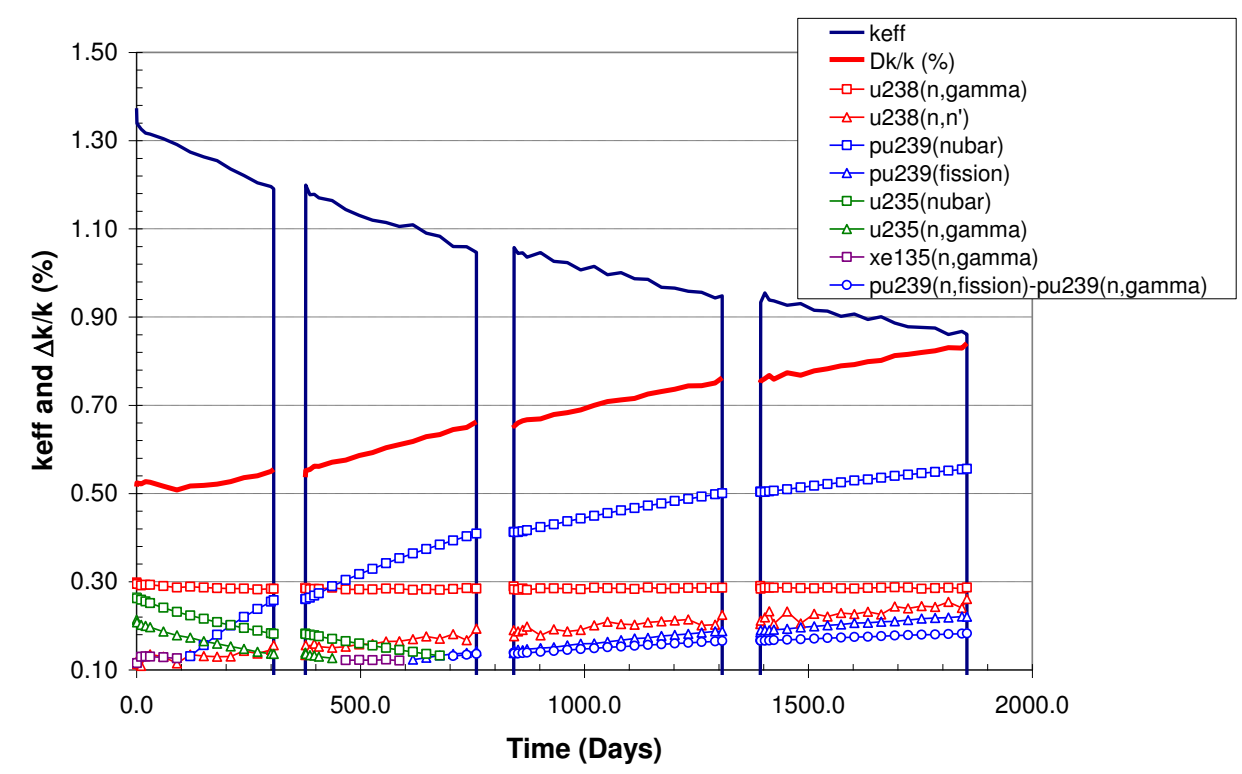

Fig. 6. $\Delta \mathrm{k} / \mathrm{k}(\%)$ predicted with TSUNAMI and the most important contributions.

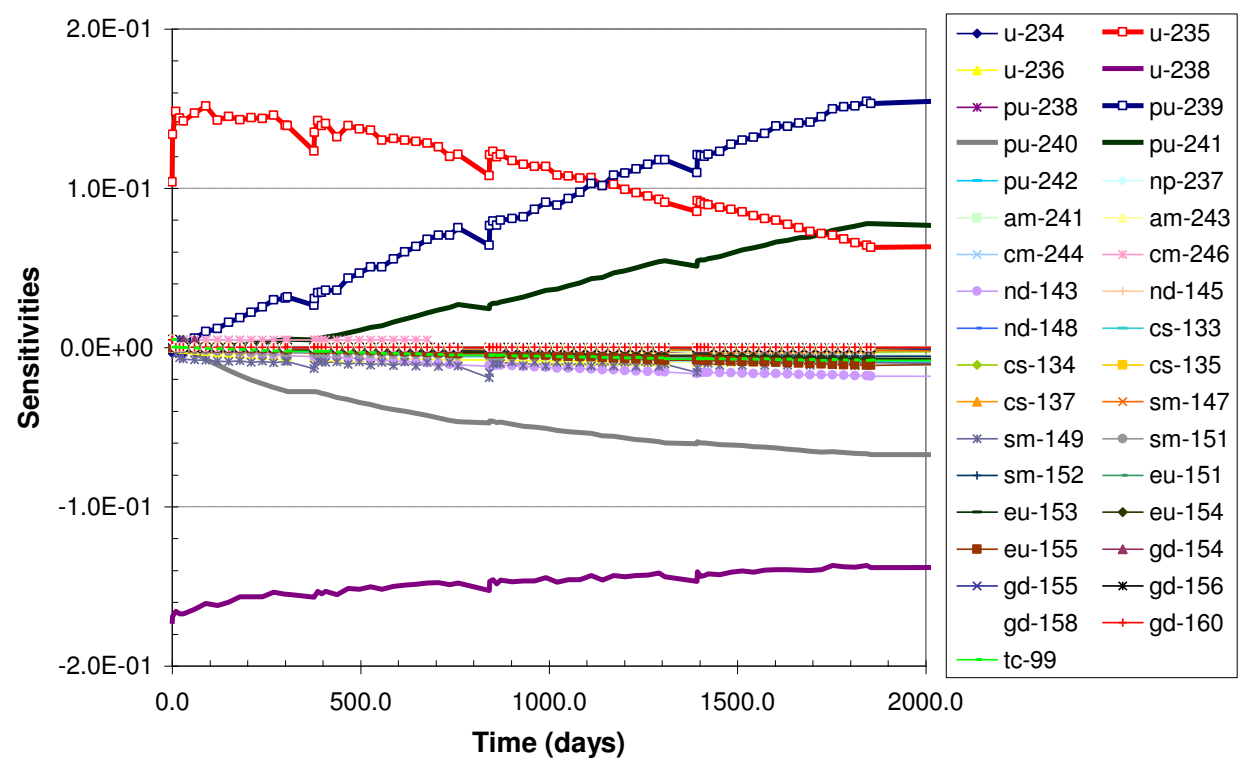

Fig. 7. Sensitivity $(\Delta \mathrm{k} / \mathrm{k} / \Delta \mathrm{N} / \mathrm{N})$ predicted with TSUNAMI and the most important contributions by isotopes.

\section{References}

1. M. N. Avramova, K.N.Ivanov, Progress in Nuclear Energy 52, (2010) 601-614

2. D. Rochman, A. J. Koning, S. C. van der Marck, A. Hogenbirk, C. M. Sciolla, Annals of Nuclear Energy 38, (2011) 942-952

3. ZZ-SCALE6.0/COVA-44G,USCD1236/02 OECDNEA Data Bank

4. N. García-Herranz, O. Cabellos, J. Sanz, J. Juan, J.C. Kuijper, Annals of Nuclear Energy 35 Issue 4, (2008) 714-730
5. J. Sanz, O. Cabellos, N. García-Herranz, NEA-1839 (2008)

6. A. Santamarina et al., JEFF Report 22 (OECD/NEA DB, 2009)

7. J.-Ch. Sublet et al., CCFE-R (10) 05, (2010) 